\title{
An Alternatively Activated Macrophage Marker CD163 in Severely Obese Patients: the Influence of Very Low-Calorie Diet and Bariatric Surgery
}

\author{
A. CINKAJZLOVÁ ${ }^{1,6}$, Z. LACINOVÁ ${ }^{1,6}$, J. KLOUČKOVÁ ${ }^{1,6}$, P. KAVÁLKOVÁ ${ }^{1}$, \\ P. TRACHTA ${ }^{2}$, M. KOSÁK ${ }^{2}$, J. KRÁTKÝ ${ }^{2}$, M. KASALICKÝ ${ }^{3}$, K. DOLEŽALOVÁ ${ }^{4}$, \\ M. MRÁZ ${ }^{1,7}$, M. HALUZÍK ${ }^{1,5,6,7}$
}

${ }^{1}$ Institute of Medical Biochemistry and Laboratory Diagnostics, Charles University and General University Hospital, Prague, Czech Republic, ${ }^{2}$ Third Department of Medicine, Charles University and General University Hospital, Prague, Czech Republic, ${ }^{3}$ Surgical Clinic of Second Faculty of Medicine, Charles University and the Military University Hospital, Prague, Czech Republic, ${ }^{4}$ Department of Surgery, OB Clinic, Prague, Czech Republic, ${ }^{5}$ Department of Obesitology, Institute of Endocrinology, Prague, Czech Republic, ${ }^{6}$ Centre for Experimental Medicine, Institute for Clinical and Experimental Medicine, Prague, Czech Republic, ${ }^{7}$ Diabetes Centre, Institute for Clinical and Experimental Medicine, Prague, Czech Republic

Received October 21, 2016

Accepted February 7, 2017

On-line April 12, 2017

\begin{abstract}
Summary
CD163 is a marker of macrophages with anti-inflammatory properties and its soluble form (sCD163) is considered a prognostic predictor of several diseases including type 2 diabetes mellitus (T2DM). We explored SCD163 levels at baseline and after very low-calorie diet (VLCD) or bariatric surgery in 32 patients with obesity ( 20 undergoing VLCD and 12 bariatric surgery), 32 obese patients with T2DM (22 undergoing VLCD and 10 bariatric surgery), and 19 control subjects. We also assessed the changes of $\mathrm{CD} 163$ positive cells of monocyte-macrophage lineage in peripheral blood and subcutaneous adipose tissue (SAT) in subset of patients. Plasma SCD163 levels were increased in obese and T2DM subjects relative to control subjects $(467.2 \pm 40.2$ and $513.8 \pm 37.0$ vs. $334.4 \pm 24.8 \mathrm{ng} / \mathrm{ml}, \mathrm{p}=0.001$ ) and decreased after both interventions. Obesity decreased percentage of $\mathrm{CD} 163+\mathrm{CD} 14+$ monocytes in peripheral blood compared to controls $(78.9 \pm 1.48$ vs. $86.2 \pm 1.31 \%, p=0.003)$ and bariatric surgery decreased CD163+CD14+HLA-DR+ macrophages in SAT $(19.4 \pm 2.32$ vs. $11.3 \pm 0.90 \%, p=0.004)$. Our data suggest that increased basal SCD163 levels are related to obesity and its metabolic complications. On the contrary, SCD163 or CD163 positive cell changes do not precisely reflect metabolic improvements after weight loss.
\end{abstract}

\section{Key words}

Obesity • Type 2 diabetes mellitus • Macrophages • Adipose tissue

\section{Corresponding author}

M. Haluzík, Centre for Experimental Medicine and Diabetes Centre, Institute for Clinical and Experimental Medicine, Vídeňská 1958, 14021 Prague 4, Czech Republic. E-mail: halm@ikem.cz

\section{Introduction}

Obesity induces chronic low-grade inflammation connected with macrophage accumulation in adipose tissue (Weisberg et al. 2003). These macrophages may contribute to inflammatory and metabolic complications of obesity (Olefsky and Glass 2010). It has been shown that both the number of macrophages and their pro-inflammatory phenotype can be changed by modifications of energy intake, energy expenditure and adipose tissue mass (Aron-Wisnewsky et al. 2009). Macrophages can exist in two main activation states: the classically activated pro-inflammatory (M1) and the 
alternatively activated anti-inflammatory (M2) macrophages regulated by pro-inflammatory and anti-inflammatory cytokines, respectively (Gustafsson et al. 2008). In our study, we focused on alternatively activated macrophages with potentially anti-inflammatory marker CD163.

$\mathrm{CD} 163$ receptor is a member of the scavenger receptor cysteine-rich superfamily (SRCR), class B. The SRCR domain forms a common structural fold with six-stranded $\beta$ sheet cradling an alpha helix. In humans, CD163 contains extracellular region of nine SRCR domains, cytoplasmic tail and one transmembrane element (Fabriek et al. 2005). The best characterized function of CD163 is endocytosis of hemoglobinhaptoglobin complexes and its expression is connected with anti-inflammatory processes (Schaer et al. 2006). Although its biological action in inflammation is not precisely known, its soluble form sCD163 was suggested as a useful predictor of the development or prognosis of several diseases including type 2 diabetes mellitus (T2DM) (Moller et al. 2011), infection by human immunodeficiency virus (Burdo et al. 2011) or several types of cancer (Lan et al. 2013, Wang et al. 2015). Interestingly, despite its suggested anti-inflammatory and scavenging properties CD163 was found to be expressed mainly on the classical pro-inflammatory monocytes (CD14++CD16-) as compared with the non-classical subset (CD14dimCD16++) despite the latter's role in tissue patrolling and control of vascular integrity (Ziegler-Heitbrock 2007).

Thus, we hypothesized that circulating sCD163 and its mRNA expression in adipose tissue may be connected to inflammatory state and modified by weightreducing interventions. To this end, we explored the changes of plasma sCD163 levels, its mRNA expression and CD163 positive cells in circulating monocyte subsets and adipose tissue in subject with simple obesity and obesity complicated by T2DM relative to lean healthy control subjects and its modulation by very low-calorie $\operatorname{diet}$ (VLCD) and bariatric surgery.

\section{Methods}

\section{Study subjects}

Thirty two obese patients, 32 obese patients with T2DM and 19 age-matched lean healthy control subjects were included into the study. Control subjects had been free of any medication and had no history of obesity or diabetes mellitus. The inclusion criteria for study subjects were age between 40 and 60 years and BMI (body mass index) higher than $35 \mathrm{~kg} / \mathrm{m}^{2}$. Patients of both genders were included as previous studies have shown that changes of CD163 are not on gender-dependent (Aristoteli et al. 2006, Fjeldborg et al. 2013). Written informed consent was signed by each subject and the studies were approved by the Human Ethics Committee, First Faculty of Medicine and General University Hospital, Prague, Czech Republic.

\section{Very low-calorie diet}

Forty two patients - 20 with obesity and 22 obese patients with T2DM underwent 3 weeks of VLCD during hospitalization at the Third Department of Medicine, General University Hospital, Prague, Czech Republic. The energy content of VLCD was $2500 \mathrm{~kJ}$ per day. Anthropometry, blood and subcutaneous adipose tissue (SAT) samples were taken before and after VLCD.

\section{Bariatric surgery}

Twenty two patients - 12 patients with obesity and 10 obese patients with T2DM underwent selected bariatric surgical procedures. The operations included gastric plication (12 patients), sleeve gastrectomy (6 patients), gastric bypass (3 patients) and gastric banding (1 patient). Anthropometry, blood and SAT samples were taken before (visit 1) and 1 month (visit 2), 6 months (visit 3) and 1 year after bariatric surgery (visit 4). During bariatric surgery, samples of visceral adipose tissue (VAT) and SAT were taken for the evaluation of mRNA expression differences between these depots.

Anthropometric examination, blood and adipose tissue sampling

All subject enrolled in the study underwent anthropometric examination and their BMI was calculated. Blood samples were taken after an overnight fasting and centrifuged for $10 \mathrm{~min}$ at $1000 \mathrm{xg}$ within $30 \mathrm{~min}$ after withdrawal. Serum or plasma aliquots were subsequently stored at $-80^{\circ} \mathrm{C}$.

Samples of SAT were obtained by needle aspiration biopsy from abdominal region after an overnight fasting and subsequently stored at $-80{ }^{\circ} \mathrm{C}$, as were samples of SAT and VAT obtained during bariatric surgery.

\section{Hormonal and biochemical assays}

Plasma sCD163 levels were measured by 
sandwich enzyme immunoassay using a commercial ELISA kit (Aviscera Bioscience, Inc., Santa Clara, USA). The whole assay including plasma dilution was done according to the manufacturer's protocol. Sensitivity was $50.0 \mathrm{pg} / \mathrm{ml}$. Serum leptin levels were measured by a commercial ELISA kit (Biovendor, Brno, Czech Republic). Sensitivity was $0.2 \mathrm{ng} / \mathrm{ml}$. Serum C-reactive protein (CRP) levels were measured by high sensitive ELISA kit (Bender Medsystems, Vienna, Austria) with a sensitivity of $3 \mathrm{pg} / \mathrm{ml}$. Insulin levels were measured by RIA kit (Cis Bio International, Gif-sur-Yvette, France). Sensitivity was $2.0 \mu \mathrm{IU} / \mathrm{ml}$. The intra- and interassay variabilities for all assays were between 5.0 and $10.0 \%$.

Biochemical parameters (blood glucose, glycated hemoglobin - HbA1c, HDL cholesterol, total cholesterol and triglycerides) were measured and LDL cholesterol was calculated at the Department of Biochemistry, General University Hospital, Prague, Czech Republic by standard laboratory methods. The homeostasis model assessment (HOMA) index was calculated according to standard equation: (fasting insulin levels $(\mathrm{mIU} / \mathrm{l}) \mathrm{x}$ fasting glucose levels $(\mathrm{mmol} / \mathrm{l})) / 22.5$.

\section{Quantitative real time PCR}

CD14+ cells were isolated from plasma using human CD14 MicroBeads and MACS columns (Miltenyi Biotec GmbH, Bergisch Gladbach, Germany) as described previously (Mraz et al. 2011). Samples of adipose tissue were homogenized on MagNA Lyser Instrument (Roche Diagnostics GmbH, Mannheim, Germany). Total RNA was extracted on MagNA Pure instrument using Magna Pure Compact RNA Isolation kit (tissue) (Roche Diagnostics GmbH, Mannheim, Germany). RNA concentration was determined from absorbance at $260 \mathrm{~nm}$ on NanoPhotometer (Implen, Munchen, Germany). Reverse transcription was performed using random primers according to the manufacturer's protocol of the High-Capacity cDNA Reverse Transcription Kits (Applied Biosystems, Foster City, CA, USA). Input amount of RNA was $250 \mu \mathrm{g}$ per reaction in case of adipose tissue and $200 \mu \mathrm{g}$ per reaction in case of CD14+ cells. Gene expression was performed on a 7500 Real-Time PCR System using TaqMan ${ }^{\circledR}$ gene Expression Assays (Applied Biosystems, Foster City, CA, USA). For reaction, a mix of TaqMan ${ }^{\circledR}$ Universal PCR Master Mix II, NO AmpErase ${ }^{\circledR}$ UNG (Applied Biosystems, Foster City, CA, USA), nucleasefree water (Fermentas Life Science, Vilnius, Lithuania) and specific TaqManGene expression Assays (Applied
Biosystems, Foster City, CA, USA) were used. Beta-2 microglobulin (B2M) was applied as endogenous reference. The formula $2^{-\mathrm{ddCt}}$ was used to calculate relative gene expression.

Isolation of stromal vascular fraction from subcutaneous adipose tissue and flow cytometry

Standard $1.5 \mathrm{~g}$ amount of adipose tissue was minced with sterile scissors and visible blood vessels were removed. Samples were washed in PBS (0.01 M PBS, pH 7.4) and digested by $0.01 \%$ collagenase (Collagenase from Clostridium histolyticum, St. Louis, MO, USA) for $30 \mathrm{~min}$ at $37^{\circ} \mathrm{C}$. After adipocyte removal, SVF fraction was washed in PBS two times.

Flow cytometry was performed from freshly isolated and filtered SVF (Falcon ${ }^{\circledR} 40 \mu \mathrm{m}$ Cell Strainer, Becton, Dickinson and Company, Franklin Lakes, USA). A total amount of $100 \mu \mathrm{l}$ of cell suspension with average $10^{6}$ cell content was labeled by monoclonal antibodies conjugated with FITC (fluorescein isothiocyanate), PE (phycoerythrin), PerCP (peridinin-chlorophyll protein complex), and APC (allophycocyanin). Used primary antibodies (Exbio Praha, a.s., Vestec, Czech Republic) included CD16 FITC, CD163 PE, HLA-DR PerCP and CD14 APC. The samples were labeled in the dark for $30 \mathrm{~min}$ at $2-8{ }^{\circ} \mathrm{C}$ and then red cells were lysed using Excellyse I (Exbio Prague, a.s., Vestec, Czech Republic) according to manufacturer's instructions. Finally, labelled cells were analyzed on BD Accuri ${ }^{\mathrm{TM}} \mathrm{C} 6$ (Becton, Dickinson and Company, Franklin Lakes, USA). Data analysis was performed using FlowJo $\mathrm{X}$ 10.0.7r2 software (FlowJo, LCC. Ashland, USA). Gating strategy for SAT was as follows: doublets were excluded, monocytes/macrophages were gated according to scatter properties, HLA-DR+ cells were determined on histogram plot and then CD163+CD14+HLA-DR+ and CD163+CD14-HLA-DR+ cells were determined as a percentage of gated monocytes/macrophages. In peripheral blood the percentage of classical, non-classical and intermediate monocyte subsets based on CD14 and CD16 expression and the percentage of CD163+CD14+ cells were determined after doublet exclusion from the monocyte gate set by scatter properties.

\section{Statistical analysis}

Statistical analysis was performed on SigmaStat 3.0 and graphs were drawn using SigmaPlot 8.0 software (SPSS Inc., Chicago, IL, USA). Results are expressed as means \pm standard error of the mean (SEM) or median 
(interquartile range). One way ANOVA/One way RM ANOVA followed by Holm-Sidak test, One way ANOVA on Ranks/One way RM ANOVA on Ranks followed by Dunn's method, unpaired t-test or Mann-Whitney Rank Sum Test, paired-test or Wilcoxon Signed-Rank were used for the assessment of intergroup differences, as appropriate. Spearman or Pearson correlation test was used to assess the association between CD163 and other parameters. The combined group of patients with healthy control subjects was used for correlation analyses. Multiple linear regression analysis using backward stepwise variable selection method was performed in combined group using parameters with significant result from Spearman or Pearson correlation test. Statistical significance was assigned to $\mathrm{p}<0.05$.

\section{Results}

\section{Baseline characteristics of the study subjects}

Obese patients had higher BMI, insulin, leptin and CRP levels and HOMA index and reduced HDL cholesterol levels compared with control subjects (Table 1). Plasma sCD163 levels were increased relative to control subjects (Fig. 1a).
Obese patients with T2DM had higher BMI, blood glucose, glycated hemoglobin, triglycerides, insulin, leptin and CRP levels and HOMA index and decreased HDL cholesterol compared with control subjects (Table 1). Plasma sCD163 levels were increased (Fig. 1a). Obese patients with T2DM had higher blood glucose, glycated hemoglobin, triglycerides and HOMA index relative to subjects with simple obesity; however, no difference in plasma sCD163 (Fig. 1a) or its mRNA expression in either SAT or CD14+ cells (Table 1) could be seen between the diabetic and obese non-diabetic group. When comparing depot-specific differences in CD163 mRNA expression in subjects enrolled in the bariatric surgery sub-study, SAT showed lower expression levels relative to VAT $(2.14 \pm 0.17$ vs. $3.24 \pm 0.41, \mathrm{p}=0.019$ ).

The effect of very low-calorie diet

Three weeks of VLCD reduced BMI, blood glucose, CRP and leptin levels and HOMA index in obese subjects both with and without T2DM (Table 2). Also, their plasma sCD163 levels were reduced after VLCD (Fig. 1b). Additionally, in obese diabetics reduced total, HDL and LDL cholesterol were found after VLCD (Table 2).

Table 1. Anthropometric, biochemical, and hormonal characteristics of study subjects at baseline.

\begin{tabular}{|c|c|c|c|}
\hline & Controls & OB & T2DM \\
\hline Number & 19 & 32 & 32 \\
\hline Age (year) & $49.95 \pm 1.43$ & $49.90 \pm 1.65$ & $53.04 \pm 1.42$ \\
\hline Body mass index $\left(\mathrm{kg} / \mathrm{m}^{2}\right)$ & $24.5(21.8-25.5)$ & $43.9(39.4-51.3)^{*}$ & $46.6(42.7-53.4)^{*}$ \\
\hline Waist circumference $(\mathrm{cm})$ & --- & $128.6 \pm 3.11$ & $134.2 \pm 3.10$ \\
\hline Blood glucose (mmol/l) & $4.80(4.53-5.15)$ & $5.00(4.70-5.73)$ & $8.75(6.65-11.65)^{* x}$ \\
\hline $\mathrm{HbAlc}(\mathrm{mmol} / \mathrm{mol})$ & $37.0(37.0-41.0)$ & $41.0(38.3-41.0)$ & $76.5(50.0-93.5)^{* x}$ \\
\hline Cholesterol (mmol/l) & $5.43 \pm 0.23$ & $5.02 \pm 0.23$ & $4.83 \pm 0.22$ \\
\hline Triglycerides (mmol/l) & $1.01(0.71-1.89)$ & $1.39(0.92-1.95)$ & $1.75(1.36-2.60)^{* x}$ \\
\hline HDL cholesterol (mmol/l) & $1.56(1.35-1.65)$ & $1.22(1.04-1.45)^{*}$ & $1.03(0.93-1.26)^{*}$ \\
\hline LDL cholesterol (mmol/l) & $3.35 \pm 0.19$ & $3.04 \pm 0.16$ & $2.83 \pm 0.21$ \\
\hline Insulin $(m I U / l)$ & $16.2(14.5-18.3)$ & $35.7(25.2-58.4)^{*}$ & $41.9(30.5-67.6)^{*}$ \\
\hline Leptin $(n g / m l)$ & $13.56 \pm 2.12$ & $48.18 \pm 4.36^{*}$ & $55.90 \pm 3.98^{*}$ \\
\hline$C R P(m g / l)$ & $0.08(0.07-0.22)$ & $1.76(0.90-3.25)^{*}$ & $2.36(1.75-3.60)^{*}$ \\
\hline HOMA index & $3.42(2.93-3.94)$ & $7.01(5.26-15.77)^{*}$ & $18.74(13.43-33.46)^{* x}$ \\
\hline CD163 mRNA expr. in SAT & $1.20 \pm 0.17$ & $1.39 \pm 0.14$ & $1.58 \pm 0.17$ \\
\hline $\begin{array}{l}\text { CD163 mRNA expr. in } \\
\text { CD14+ cells }\end{array}$ & $1.07 \pm 0.12$ & $0.88 \pm 0.09$ & $1.03 \pm 0.09$ \\
\hline
\end{tabular}

$\mathrm{OB}$, non-diabetic obese subjects; T2DM, obese subjects with type 2 diabetes mellitus; CRP, C-reactive protein; SAT, subcutaneous adipose tissue. Values are mean \pm SEM or median (interquartile range). $* p<0.05$ vs. healthy control subjects; One way ANOVA/ANOVA on Ranks, ${ }^{x} \mathrm{p}<0.05$ vs. OB subjects; unpaired t-test or Mann-Whitney Rank Sum Test. 
a) SCD163 levels: basal state before intervention

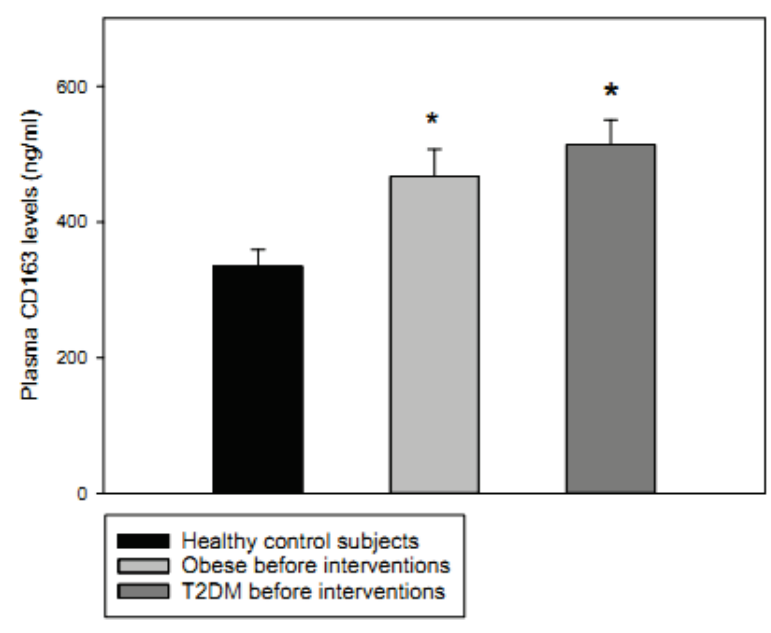

c) SCD163 levels: effect of bariatric surgery in OB patients

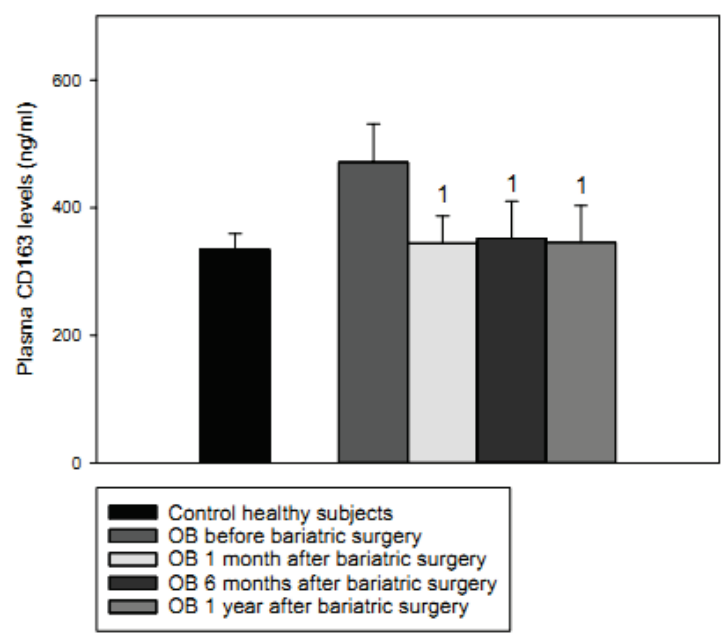

b) sCD163 levels: VLCD effect

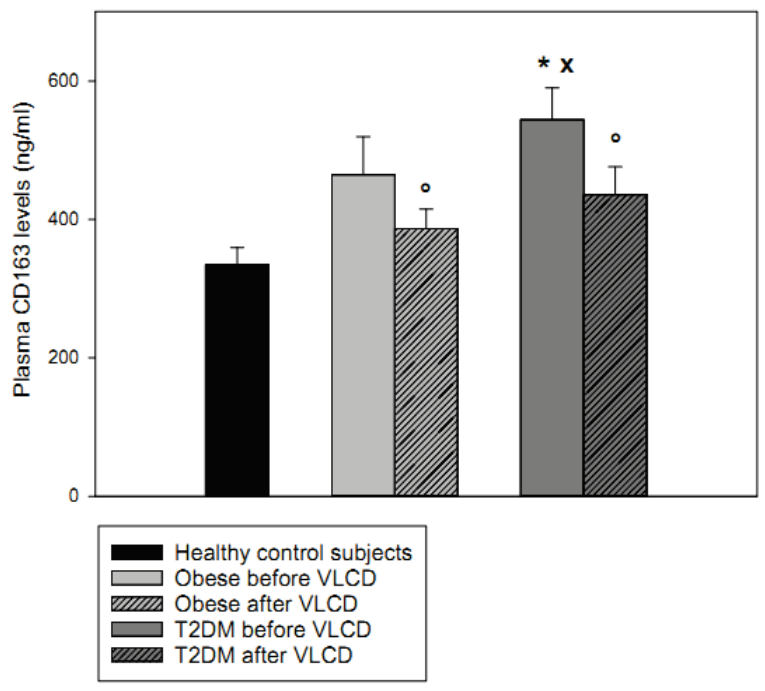

d) SCD163 levels: effect of bariatric surgery in T2DM patients

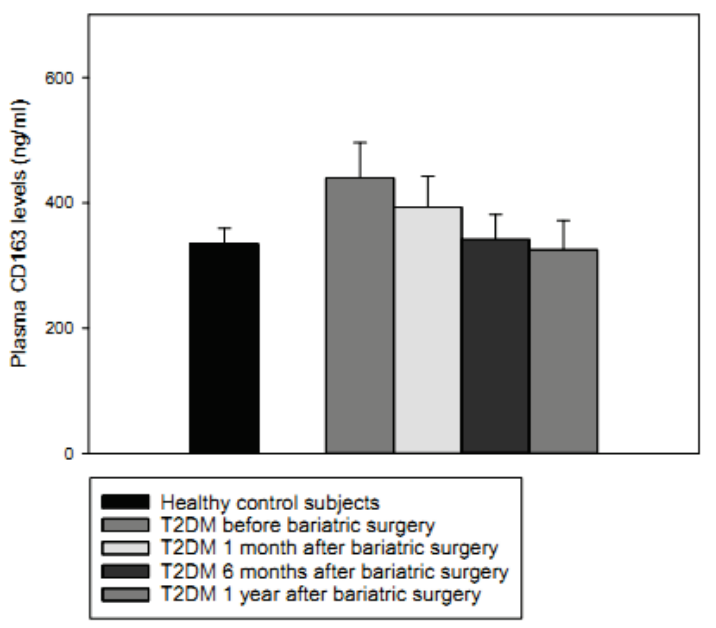

Fig. 1. Plasma SCD163 levels: before interventions (a), effect of VLCD (b) and bariatric surgery in obese (c) and T2DM subjects (d). $\mathrm{OB}$, non-diabetic obese subjects; T2DM, obese subjects with type 2 diabetes mellitus. Values are mean \pm SEM or median (interquartile range). $* p<0.05$ vs. healthy control subjects; One way ANOVA/ANOVA on Ranks, ${ }^{\circ} p<0.05$ vs. before VLCD; paired t-test or Wilcoxon Signed Rank Test, ${ }^{x} p<0.05$ vs. OB subjects; unpaired t-test or Mann-Whitney Rank Sum Test. ${ }^{1} p<0.05$ vs. before bariatric surgery; One Way RM ANOVA/One way RM ANOVA on Ranks.

\section{The effect of bariatric surgery}

Bariatric surgery in obese patients without T2DM decreased BMI, glycated hemoglobin, leptin (Table 3) and plasma sCD163 levels (Fig. 1c) relative to baseline and these changes lasted throughout the study.

Bariatric surgery in obese patients with T2DM decreased BMI, glycated hemoglobin, insulin and leptin levels and HOMA index relative to baseline and these changes lasted throughout the study (Table 3). HDL cholesterol decreased transiently 1 month after surgery. Plasma sCD163 levels tended to decrease after bariatric surgery but the difference did not reach statistical significance (Fig. 1d).

\section{Relationship of CD163 to other studied parameters}

In a combined group of obese patients with and without T2DM and control subjects CD163 mRNA expression in SAT positively correlated with serum triglycerides $(\mathrm{R}=0.266, \mathrm{p}=0.017)$. Plasma sCD163 levels positively correlated with $\mathrm{BMI}(\mathrm{R}=0.407, \mathrm{p}<0.001)$, waist circumference $(\mathrm{p}=0.007, \mathrm{R}=0.395)$, blood glucose $(\mathrm{R}=0.413$, $\mathrm{p}<0.001)$, glycated hemoglobin $(\mathrm{R}=0.567$, $\mathrm{p}<0.001)$, triglycerides $(\mathrm{R}=0.307, \mathrm{p}=0.005)$, insulin $(\mathrm{R}=0.592, \quad \mathrm{p}<0.001), \quad$ leptin $\quad(\mathrm{R}=0.389, \quad \mathrm{p}<0.001)$, CRP levels $(\mathrm{R}=0.525, \mathrm{p}<0.001)$ and HOMA index $(\mathrm{R}=0.587, \mathrm{p}<0.001)$ and negatively with HDL cholesterol $(\mathrm{R}=-0.478, \mathrm{p}<0.001)$. CD163 mRNA expression in 
Table 2. The effect of VLCD on anthropometric, biochemical, and hormonal characteristics of obese subjects with and without type 2 diabetes mellitus.

\begin{tabular}{|c|c|c|c|c|}
\hline & OB before & OB after & T2DM before & T2DM after \\
\hline Number & 20 & 20 & 22 & 22 \\
\hline Age (year) & $51.9 \pm 1.87$ & --- & $55.1 \pm 1.53$ & --- \\
\hline Body mass index $\left(\mathrm{kg} / \mathrm{m}^{2}\right)$ & $48.4 \pm 1.95^{*}$ & $46.2 \pm 1.98 * \circ$ & $50.0 \pm 1.62 *$ & $46.9 \pm 1.52 * \circ$ \\
\hline Blood glucose (mmol/l) & $5.00(4.70-6.25)$ & $4.90(4.45-5.20)^{\circ}$ & $9.05(7.20-12.0)^{* x}$ & $7.00(5.60-9.50)^{* \circ x}$ \\
\hline Waist circumference (cm) & $135.6 \pm 4.63$ & $136.9 \pm 3.36$ & $131.8 \pm 4.36$ & $126.03 \pm 3.45$ \\
\hline $\mathrm{HbAlc}(\mathrm{mmol} / \mathrm{mol})$ & $43.0(40.0-48.5)$ & --- & $83.5(58.0-97.0)^{* \mathrm{x}}$ & --- \\
\hline Cholesterol (mmol/l) & $5.13 \pm 0.33$ & $4.67 \pm 0.32$ & $4.83 \pm 0.29$ & $3.76 \pm 0.16^{* \circ \mathrm{x}}$ \\
\hline Triglycerides (mmol/l) & $1.44(0.93-2.17)$ & $0.96(0.90-1.66)$ & $1.87(1.61-2.70)^{* x}$ & $1.77(1.41-2.36)^{* x}$ \\
\hline HDL cholesterol $(\mathrm{mmol} / \mathrm{l})$ & $1.18(1.04-1.46)^{*}$ & $1.13(0.96-1.44)^{*}$ & $1.01(0.90-1.26)^{*}$ & $0.96(0.84-1.00)^{* \circ x}$ \\
\hline LDL cholesterol (mmol/l) & $3.09 \pm 0.23$ & $2.84 \pm 0.26$ & $2.71 \pm 0.23^{*}$ & $2.05 \pm 0.17 * 0 \mathrm{x}$ \\
\hline Insulin (mIU/l) & $32.0(23.4-62.3)^{*}$ & $34.5(20.0-45.8)^{* \circ}$ & $40.7(32.5-57.8)^{*}$ & $44.0(31.3-52.1)^{*}$ \\
\hline Leptin $(n g / m l)$ & $54.2 \pm 5.83^{*}$ & $49.8 \pm 6.27^{*}$ & $60.1 \pm 4.51^{*}$ & $51.9 \pm 5.05^{*}$ \\
\hline$C R P(m g / l)$ & $2.09 \pm 0.53 *$ & $1.63 \pm 0.46^{* \circ}$ & $2.32 \pm 0.29^{*}$ & $1.43 \pm 0.23 * \circ$ \\
\hline HOMA index & $6.6(5.1-18.3)^{*}$ & $7.9(3.7-10.8)^{* \circ}$ & $18.1(14.7-32.9)^{* \mathrm{x}}$ & $11.8(10.8-17.1)^{* \circ \mathrm{x}}$ \\
\hline CD163 mRNA expr. in $S A T$ & $1.59 \pm 0.20$ & $1.59 \pm 0.13$ & $1.93 \pm 0.21$ & $1.85 \pm 0.19$ \\
\hline CD163 mRNA expr. in CD14+ cells & $0.89 \pm 0.11$ & $0.81 \pm 0.07$ & $0.92 \pm 0.14$ & $0.77 \pm 0.12$ \\
\hline
\end{tabular}

$\mathrm{OB}$, non-diabetic obese subjects; T2DM, obese subjects with type 2 diabetes mellitus; CRP, C-reactive protein; SAT, subcutaneous adipose tissue. Values are mean \pm SEM or median (interquartile range). $* p<0.05$ vs. healthy control subjects; One way ANOVA/ANOVA on Ranks, data are presented in Table 1 , column Controls, ${ }^{\circ} \mathrm{p}<0.05$ vs. before VLCD; paired t-test or Wilcoxon Signed Rank Test, ${ }^{x} \mathrm{p}<0.05$ vs. OB subjects; unpaired t-test or Mann-Whitney Rank Sum Test.

CD14+ cells did not correlate with any of the measured parameters.

Multiple linear regression analysis was performed in the same group. None of the included parameters were independent predictors of CD163 mRNA expression in SAT or CD14+ cells, while sCD163 levels were independently associated with glycated hemoglobin $(p<0.001$, Standard $\beta=3.489)$ and CRP $(p<0.001$, Standard $\beta=43.530$ ). The adjusted Adj $R^{2}$ was 0.522 for the whole analysis.

Furthermore, we found a positive correlation of alanine aminotransferase levels and $\operatorname{sCD} 163(\mathrm{R}=0.440$, $\mathrm{p}=0.040$ ) in subjects who underwent bariatric surgery. In addition, we found a strong positive correlation between CD163 mRNA expression in VAT and basal sCD163 levels $(\mathrm{R}=0.803, \mathrm{p}=0.016)$.

Changes of immunocompetent cell composition in peripheral blood and subcutaneous adipose tissue

We studied the changes of immunocompetent cell composition by flow cytometry in 11 obese patients with and without T2DM from the bariatric surgery sub-study, who underwent gastric plication.

In peripheral blood populations of classical, non-classical and intermediate monocytes based on CD14 and CD16 expression and populations of CD163+ monocytes were defined. At baseline, the patients had decreased classical monocytes (CD14++CD16-) and CD163+CD14+ cells and increased non-classical monocytes (CD14dimCD16++) compared with control subjects and these changes lasted also after gastric plication (Table 4).

CD163+CD14+ cells are probably recruited from classical monocyte subset. A strong positive correlation between the classical monocyte subset and CD163+CD14+ monocytes was found $(\mathrm{R}=0.939, \mathrm{p}<0.001)$, while only weak inverse correlation between intermediate and CD163+CD14+ monocytes could be seen $(\mathrm{R}=-0.302$, $\mathrm{p}=0.049)$. CD163+CD14+ cells and non-classical monocytes did not correlate.

In the stromal vascular fraction of SAT CD163+CD14+HLA-DR+ and CD163+CD14-HLA-DR+ populations were determined from the gate for monocytes/macrophages. Percentage of CD163+CD14+ HLA-DR + cells decreased and percentage of CD163+CD14-HLA-DR+ cells increased 6 months after gastric plication relative to baseline and 1 month after surgery (Table 4). 


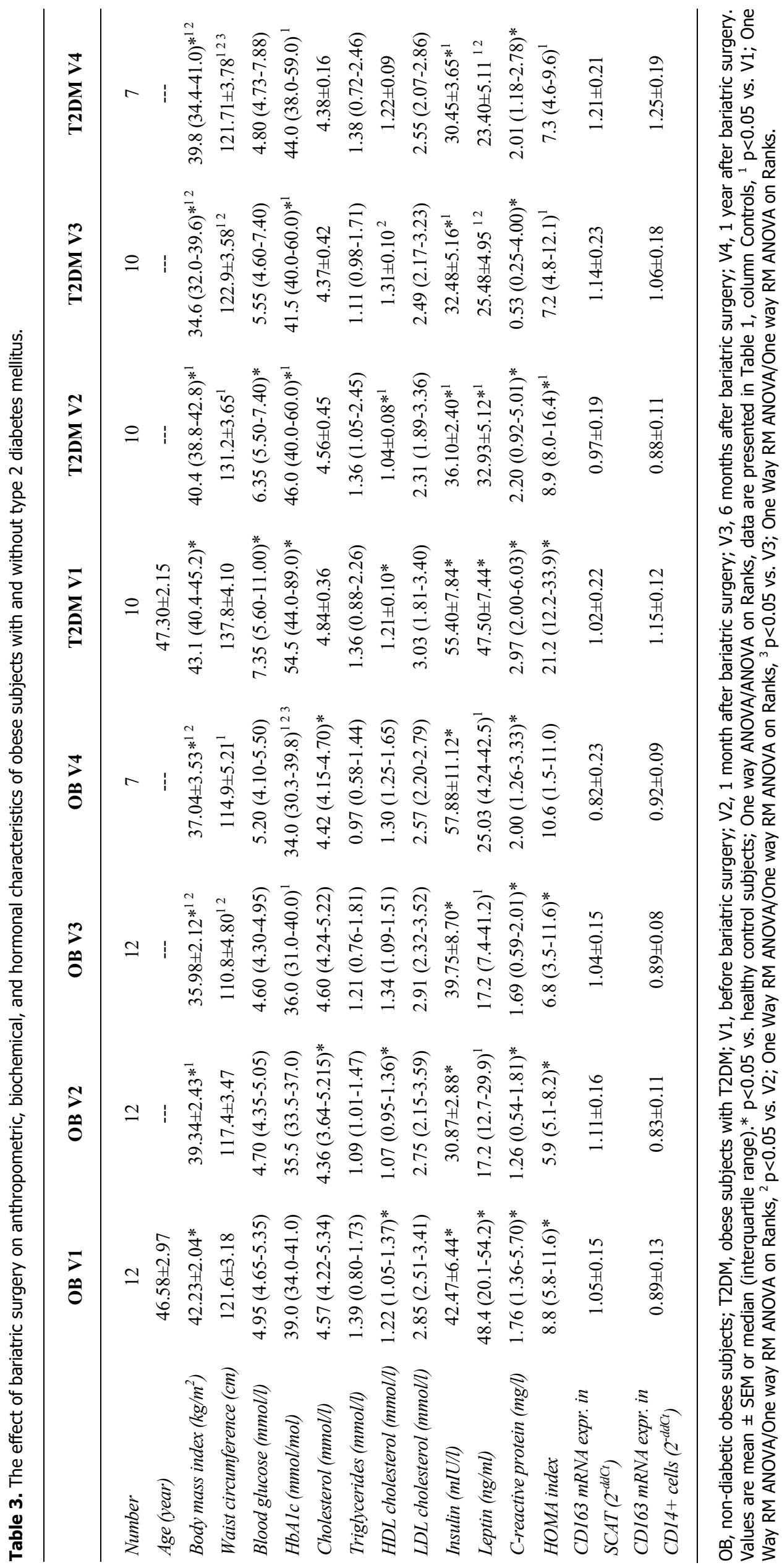


Table 4. The influence of gastric plication on flow cytometry findings in obese patients with and without type 2 diabetes mellitus: cell populations in peripheral blood and stromal vascular fraction of SAT.

Controls OB+T2DM V1 OB+T2DM V2 OB+T2DM V3

\begin{tabular}{llcccc}
\hline & Number & 12 & 11 & 10 & 10 \\
& Classical monocytes (\%) & $80.9 \pm 1.37$ & $74.7 \pm 1.48^{*}$ & $75.7 \pm 1.58^{*}$ & $75.8 \pm 1.17^{*}$ \\
Peripheral blood & Intermediate monocytes (\%) & $6.17 \pm 0.58$ & $7.40 \pm 0.61$ & $6.95 \pm 0.47$ & $7.01 \pm 0.38$ \\
& Non-classical monocytes (\%) & $3.30 \pm 0.61$ & $7.02 \pm 0.96^{*}$ & $7.04 \pm 0.92^{*}$ & $8.53 \pm 1.04^{*}$ \\
& CD163+CD14+ cells (\%) & $86.2 \pm 1.31$ & $78.9 \pm 1.48^{*}$ & $81.1 \pm 1.65^{*}$ & $80.7 \pm 1.07^{*}$ \\
Stromal vascular & Number & & 11 & 11 & 9 \\
fraction of SAT & CD163+CD14+HLA-DR+(\%) & --- & $19.4 \pm 2.32$ & $16.7 \pm 1.80$ & $11.3 \pm 0.90^{12}$ \\
& CD163+CD14-HLA-DR+(\%) & --- & $4.17 \pm 0.49$ & $3.83 \pm 0.52$ & $7.56 \pm 0.99^{12}$ \\
\hline
\end{tabular}

$\mathrm{OB}$, non-diabetic obese subjects; T2DM, obese subjects with type 2 diabetes mellitus; V1, before bariatric surgery; V2, 1 month after bariatric surgery; V3, 6 months after bariatric surgery; SAT, subcutaneous adipose tissue. Values are mean \pm SEM. $* p<0.05$ vs. healthy control subjects; One way ANOVA/ANOVA on Ranks, ${ }^{1} p<0.05$ vs. V1; One Way RM ANOVA/One way RM ANOVA on Ranks, ${ }^{2} \mathrm{p}<0.05$ vs. V2; One Way RM ANOVA/One way RM ANOVA on Ranks.

\section{Discussion}

Subclinical inflammation occurring primarily in the adipose tissue plays an important role in the development of metabolic complications of obesity and ultimately in the increased risk of cardiovascular morbidity and mortality. Here we studied the changes of sCD163 (a marker of alternatively activated macrophages), peripheral blood $\mathrm{CD} 163+$ cells and two subpopulations of CD163+ cells in the stromal vascular fraction of subcutaneous adipose tissue in patients with obesity with or without type 2 diabetes mellitus. To explore the role of CD163 in the regulation of systemic and adipose tissue inflammatory response, we prospectively studied the changes of the above mentioned parameters after selected weight-reducing interventions that included very low-calorie diet and bariatric surgery.

Plasma SCD163 is produced by shedding of the membrane form of CD163 receptor (Droste et al. 1999). Alternatively activated macrophages expressing CD163 exert anti-inflammatory properties based on the function of CD163 as erythroblast adhesion receptor, receptor for tumor necrosis factor-like weak inducer of apoptosis or receptor for distinct pathogens (Van Gorp et al. 2010). Furthermore, soluble sCD163 has potential anti-inflammatory effects as an inhibitor of phorbol ester-induced $\mathrm{T}$ lymphocytes activation and proliferation as well as matrix metalloproteinase-9 activity (Frings $e t$ al. 2002, Hogger and Sorg 2001). It was previously described that sCD163 levels are increased in several diseases including obesity and T2DM (Moller et al. 2011, Parkner et al. 2012, Zanni et al. 2012). In agreement with these data, we found increased baseline sCD163 levels in both obese patients with and without T2DM and positive correlations between $\mathrm{SCD} 163$ and assessed biochemical parameters such as serum triglycerides, blood glucose and glycated hemoglobin confirming its association with metabolic dysregulations present in obesity. Moreover, multiple linear regression analysis revealed that glycated hemoglobin and C-reactive protein levels were independent predictors of sCD163 levels. As expected (Fjeldborg et al. 2013, Kazankov et al. 2015a), both VLCD and bariatric surgery decreased sCD163 which corresponds with global metabolic improvements after both interventions. Taken together, our results suggest that $\mathrm{sCD} 163$ could be useful as a marker of global metabolic risk of obese subjects reflecting both the inflammatory response and the metabolic control.

In contrast to changes of circulating sCD163 levels, mRNA expression of CD163 in SAT or in $\mathrm{CD} 14+$ cells was not affected by obesity, diabetes or weight reducing interventions. These results are in disagreement with some previously published studies (Fjeldborg et al. 2014, Shakeri-Manesch et al. 2009), which found increased mRNA expression of CD163 in SAT in obese subjects. In our study, only patients enrolled in the VLCD sub-study tended to have elevated mRNA expression in SAT compared with control subjects, but the difference did not reach statistical significance. We also did not find the previously described association between circulating sCD163 levels and its mRNA expression in SAT (data not shown) (Kracmerova et al. 2014). The lack of association between circulating SCD163 and its mRNA expression in 
SAT in our study may suggest that SCD163 could come from other substantial sources than subcutaneous adipose tissue. For instance, enhanced production of sCD163 was previously described in obese subjects with non-alcoholic fatty liver disease (NAFLD) (Kazankov et al. 2015a,b). In line with this possibility, we found a positive correlation of alanine aminotransferase levels and sCD163 indirectly supporting a possible interconnection between circulating SCD163 and NAFLD. Furthermore, another potential source of sCD163, which can respond differently to metabolic state than SAT, might be the visceral adipose tissue depot (VAT). Here, we observed a higher mRNA expression of CD163 in VAT relative to SAT as well as a positive correlation between CD163 mRNA expression in VAT and basal sCD163 levels suggesting that VAT could be in fact a more important source of circulating sCD163 than subcutaneous fat in our patients. These data are in line with the previously described positive correlation between VAT CD163 mRNA expression or VAT to SAT depot ratio and sCD163 and with a multivariate analysis proving VAT CD163 mRNA expression as independent predictor of $\mathrm{SCD} 163$ in obese T2DM males (Sorensen et al. 2015). The difference between SAT and VAT CD163 mRNA expression might be most probably explained by increased macrophage numbers in VAT versus SAT (Harman-Boehm et al. 2007).

We also explored the differences in circulating monocyte subsets between obese and lean subjects based on previously described findings suggesting their modulation by obesity and its complications (Hristov and Weber 2011, Poitou et al. 2011). Similarly to previous studies (Hristov and Weber 2011, Rogacev et al. 2010), we found lower proportion of classical monocytes (CD14++CD16-) and higher percentage of non-classical monocytes (CD14dimCD16++) in obese patients relative to lean control subjects. In a selected subset of patients, we studied the influence of gastric plication on different subsets of CD163 positive monocytes in peripheral blood. Interestingly, weight loss induced by gastric plication did not have any significant effect on the monocyte subsets. These results are in disagreement with a previously published study by Poitou et al. (2011), where the percentage of both non-classical and intermediate monocytes decreased after gastric bypass surgery. Moreover, we confirmed that $\mathrm{CD} 163+\mathrm{CD} 14+$ cells are recruited from a subset of classical monocytes by analyzing the CD163 fluorescence signal from individual monocyte subsets (data not shown) (Ziegler-Heitbrock
2007). Lower percentage of CD163+ cells was also found in the subset of intermediate monocytes (CD14++CD16+), but we conclude that these cells might present a reservoir for classical monocytes (Hijdra et al. 2013).

In the stromal vascular fraction of SAT, we evaluated the changes of two populations of CD163 positive cells differing by CD14 expression after bariatric surgery. CD163 is generally used as a marker of alternatively activated (M2) macrophages with anti-inflammatory properties and it was suggested that CD163 is expressed exclusively on myeloid lineage (Fabriek et al. 2005). Here, M2 macrophage subpopulation (defined as CD163+CD14+HLA-DR+ cells) decreased 6 months after bariatric surgery as compared with baseline and 1 month after surgery. Interestingly, the second population of $\mathrm{CD} 14$ negative cells $(C D 163+C D 14-H L A-D R+)$ significantly increased 6 months after bariatric surgery relative to baseline and 1 month after surgery. The precise origin of the CD14 negative population is unknown and our study design does not allow us to directly answer this question. The most likely explanation is that these CD163 positive cells represent a population of dendritic cells derived from myeloid lineage (Maniecki et al. 2006), which share some antigens with cells of monocyte/macrophage system. Other possible origins of CD14 negative cells may include 1) a population of macrophages developed in adipose tissue from preadipocytes (Charriere et al. 2003), 2) a population of preadipocytes with macrophage-like phenotype (Cousin et al. 1999) or 3) a population of macrophages, which do not express CD14 similarly to resident macrophages in the intestine (Smith et al. 1997). In general, these cells have some features of macrophages such as phagocytosis, anti-microbial activity or expression of antigens typical for macrophages (Cousin et al. 1999, Charriere et al. 2003). Another important question is the possible phenotypic difference in the CD14 positive and the CD14 negative cell populations in the adipose tissue. In our study, bariatric surgery decreased the entire CD163 positive population as well as its CD14 positive subset, while only its CD14 negative fraction was elevated. These data suggest that the association of M2 macrophage phenotype with positive metabolic effects in humans may be more complex than anticipated by some previously published studies (Bourlier et al. 2008, Zeyda et al. 2007). Our results also differ from a recently published immunochemistry study (Aron-Wisnewsky et al. 2009) where M2 macrophages 
increased after Roux-en-Y gastric bypass. Nevertheless, the disagreement between this and our study could be due to the usage of the CD206 marker for the identification of alternatively activated macrophages and from different methodologies used in these two studies.

In conclusion, we have demonstrated that obesity

both with and without T2DM increases sCD163 levels without affecting CD163 mRNA expression in subcutaneous adipose tissue or CD14+ monocytes in blood. Furthermore, obesity increased the non-classical subset and decreased the classical subset of monocytes in blood. The decrease of classical monocytes was in relation with the reduction of CD163+CD14+ monocytes in peripheral blood. In subcutaneous adipose tissue of obese subjects, we identified two CD163 positive cell populations, which responded differently to body weight reduction after gastric plication. Taken together, increase of sCD163 levels could be useful for prediction of obesity and its metabolic complications while sCD163 or CD163 positive cells changes in peripheral blood or subcutaneous adipose tissue do not reflect precisely metabolic improvements after weight loss.

\section{Conflict of Interest}

There is no conflict of interest.

\section{Acknowledgements}

Supported by RVO VFN64165, NV15-26854A, MO 1012 and $\mathrm{MH} \mathrm{CZ} \mathrm{-} \mathrm{DRO} \mathrm{(Institute} \mathrm{for} \mathrm{Clinical} \mathrm{and}$ Experimental Medicine - IKEM, IN 000023001).

\section{References}

ARISTOTELI LP, MOLLER HJ, BAILEY B, MOESTRUP SK, KRITHARIDES L: The monocytic lineage specific soluble CD163 is a plasma marker of coronary atherosclerosis. Atherosclerosis 184: 342-347, 2006.

ARON-WISNEWSKY J, TORDJMAN J, POITOU C, DARAKHSHAN F, HUGOL D, BASDEVANT A, AISSAT A, GUERRE-MILLO M, CLEMENT K: Human adipose tissue macrophages: $\mathrm{m} 1$ and $\mathrm{m} 2$ cell surface markers in subcutaneous and omental depots and after weight loss. J Clin Endocrinol Metab 94: 4619-4623, 2009.

BOURLIER V, ZAKAROFF-GIRARD A, MIRANVILLE A, DE BARROS S, MAUMUS M, SENGENES C, GALITZKY J, LAFONTAN M, KARPE F, FRAYN KN, BOULOUMIE A: Remodeling phenotype of human subcutaneous adipose tissue macrophages. Circulation 117: 806-815, 2008.

BURDO TH, LENTZ MR, AUTISSIER P, KRISHNAN A, HALPERN E, LETENDRE S, ROSENBERG ES, ELLIS RJ, WILLIAMS KC: Soluble CD163 made by monocyte/macrophages is a novel marker of HIV activity in early and chronic infection prior to and after anti-retroviral therapy. J Infect Dis 204: 154-163, 2011.

CHARRIERE G, COUSIN B, ARNAUD E, ANDRE M, BACOU F, PENICAUD L, CASTEILLA L: Preadipocyte conversion to macrophage. Evidence of plasticity. J Biol Chem 278: 9850-9855, 2003.

COUSIN B, MUNOZ O, ANDRE M, FONTANILLES AM, DANI C, COUSIN JL, LAHARRAGUE P, CASTEILLA L, PENICAUD L: A role for preadipocytes as macrophage-like cells. FASEB J 13: 305-312, 1999.

DROSTE A, SORG C, HOGGER P: Shedding of CD163, a novel regulatory mechanism for a member of the scavenger receptor cysteine-rich family. Biochem Biophys Res Commun 256: 110-113, 1999.

FABRIEK BO, DIJKSTRA CD, VAN DEN BERG TK: The macrophage scavenger receptor CD163. Immunobiology 210: 153-160, 2005.

FERRERO E, HSIEH CL, FRANCKE U, GOYERT SM: CD14 is a member of the family of leucine-rich proteins and is encoded by a gene syntenic with multiple receptor genes. J Immunol 145: 331-336, 1990.

FJELDBORG K, CHRISTIANSEN T, BENNETZEN M, MOLLER HJ, PEDERSEN SB, RICHELSEN B: The macrophage-specific serum marker, soluble CD163, is increased in obesity and reduced after dietary-induced weight loss. Obesity (Silver Spring) 21: 2437-2443, 2013.

FJELDBORG K, PEDERSEN SB, MOLLER HJ, CHRISTIANSEN T, BENNETZEN M, RICHELSEN B: Human adipose tissue macrophages are enhanced but changed to an anti-inflammatory profile in obesity. J Immunol Res 2014: 309548, 2014.

FRINGS W, DREIER J, SORG C: Only the soluble form of the scavenger receptor CD163 acts inhibitory on phorbol ester-activated T-lymphocytes, whereas membrane-bound protein has no effect. FEBS Lett 526: 93-96, 2002.

GUSTAFSSON C, MJOSBERG J, MATUSSEK A, GEFFERS R, MATTHIESEN L, BERG G, SHARMA S, BUER J, ERNERUDH J: Gene expression profiling of human decidual macrophages: evidence for immunosuppressive phenotype. PLoS One 3: e2078, 2008. 
HARMAN-BOEHM I, BLUHER M, REDEL H, SION-VARDY N, OVADIA S, AVINOACH E, SHAI I, KLOTING N, STUMVOLL M, BASHAN N, RUDICH A: Macrophage infiltration into omental versus subcutaneous fat across different populations: effect of regional adiposity and the comorbidities of obesity. J Clin Endocrinol Metab 92: 2240-2247, 2007.

HIJDRA D, VORSELAARS AD, GRUTTERS JC, CLAESSEN AM, RIJKERS GT: Phenotypic characterization of human intermediate monocytes. Front Immunol 4: 339, 2013.

HOGGER P, SORG C: Soluble CD163 inhibits phorbol ester-induced lymphocyte proliferation. Biochem Biophys Res Commun 288: 841-843, 2001.

HRISTOV M, WEBER C: Differential role of monocyte subsets in atherosclerosis. Thromb Haemost 106: 757-762, 2011.

JONES EY, FUGGER L, STROMINGER JL, SIEBOLD C: MHC class II proteins and disease: a structural perspective. Nat Rev Immunol 6: 271-282, 2006.

KAZANKOV K, TORDJMAN J, MOLLER HJ, VILSTRUP H, POITOU C, BEDOSSA P, BOUILLOT JL, CLEMENT K, GRONBAEK H: The macrophage activation marker sCD163 is independently associated with NAFLD severity in morbid obesity and reduced by bariatric surgery. J Gastroenterol Hepatol 30: 1293-1300, 2015a.

KAZANKOV K, MOLLER HJ, LANGE A, BIRKEBAEK NH, HOLLAND-FISCHER P, SOLVIG J, HORLYCK A, KRISTENSEN K, RITTIG S, HANDBERG A, VILSTRUP H, GRONBAEK H: The macrophage activation marker sCD163 is associated with changes in NAFLD and metabolic profile during lifestyle intervention in obese children. Pediatr Obes 10: 226-233, 2015 b.

KRACMEROVA J, ROSSMEISLOVA L, KOVACOVA Z, KLIMCAKOVA E, POLAK J, TENCEROVA M, MALISOVA L, STICH V, LANGIN D, SIKLOVA M: Soluble CD163 is associated with CD163 mRNA expression in adipose tissue and with insulin sensitivity in steady-state condition but not in response to calorie restriction. J Clin Endocrinol Metab 99: E528-E535, 2014.

LAN C, HUANG X, LIN S, HUANG H, CAI Q, WAN T, LU J, LIU J: Expression of M2-polarized macrophages is associated with poor prognosis for advanced epithelial ovarian cancer. Technol Cancer Res Treat 12: 259-267, 2013.

MANIECKI MB, MOLLER HJ, MOESTRUP SK, MOLLER BK: CD163 positive subsets of blood dendritic cells: the scavenging macrophage receptors CD163 and CD91 are coexpressed on human dendritic cells and monocytes. Immunobiology 211: 407-417, 2006.

MOLLER HJ, FRIKKE-SCHMIDT R, MOESTRUP SK, NORDESTGAARD BG, TYBJAERG-HANSEN A: Serum soluble CD163 predicts risk of type 2 diabetes in the general population. Clin Chem 57: 291-297, 2011.

MRAZ M, LACINOVA Z, DRAPALOVA J, HALUZIKOVA D, HORINEK A, MATOULEK M, TRACHTA P, KAVALKOVA P, SVACINA S, HALUZIK M: The effect of very-low-calorie diet on mRNA expression of inflammation-related genes in subcutaneous adipose tissue and peripheral monocytes of obese patients with type 2 diabetes mellitus. J Clin Endocrinol Metab 96: E606-E613, 2011.

OLEFSKY JM, GLASS CK: Macrophages, inflammation, and insulin resistance. Annu Rev Physiol 72: 219-246, 2010.

PARKNER T, SORENSEN LP, NIELSEN AR, FISCHER CP, BIBBY BM, NIELSEN S, PEDERSEN BK, MOLLER HJ: Soluble CD163: a biomarker linking macrophages and insulin resistance. Diabetologia 55: 1856-1862, 2012.

POITOU C, DALMAS E, RENOVATO M, BENHAMO V, HAJDUCH F, ABDENNOUR M, KAHN JF, VEYRIE N, RIZKALLA S, FRIDMAN WH, SAUTES-FRIDMAN C, CLEMENT K, CREMER I: CD14dimCD16+ and CD14+CD16+ monocytes in obesity and during weight loss: relationships with fat mass and subclinical atherosclerosis. Arterioscler Thromb Vasc Biol 31: 2322-2330, 2011.

ROGACEV KS, ULRICH C, BLOMER L, HORNOF F, OSTER K, ZIEGELIN M, CREMERS B, GRENNER Y, GEISEL J, SCHLITT A, KOHLER H, FLISER D, GIRNDT M, HEINE GH: Monocyte heterogeneity in obesity and subclinical atherosclerosis. Eur Heart J 31: 369-376, 2010.

SCHAER CA, SCHOEDON G, IMHOF A, KURRER MO, SCHAER DJ: Constitutive endocytosis of CD163 mediates hemoglobin-heme uptake and determines the noninflammatory and protective transcriptional response of macrophages to hemoglobin. Circ Res 99: 943-950, 2006. 
SHAKERI-MANESCH S, ZEYDA M, HUBER J, LUDVIK B, PRAGER G, STULNIG TM: Diminished upregulation of visceral adipose heme oxygenase-1 correlates with waist-to-hip ratio and insulin resistance. Int $J$ Obes (Lond) 33: 1257-1264, 2009.

SMITH PD, JANOFF EN, MOSTELLER-BARNUM M, MERGER M, ORENSTEIN JM, KEARNEY JF, GRAHAM MF: Isolation and purification of CD14-negative mucosal macrophages from normal human small intestine. J Immunol Methods 202: 1-11, 1997.

SORENSEN LP, PARKNER T, SONDERGAARD E, BIBBY BM, MOLLER HJ, NIELSEN S: Visceral obesity is associated with increased soluble CD163 concentration in men with type 2 diabetes mellitus. Endocr Connect 4: 27-36, 2015.

THOMAS G, TACKE R, HEDRICK CC, HANNA RN: Nonclassical patrolling monocyte function in the vasculature. Arterioscler Thromb Vasc Biol 35: 1306-1316, 2015.

VAN GORP H, DELPUTTE PL, NAUWYNCK HJ: Scavenger receptor CD163, a Jack-of-all-trades and potential target for cell-directed therapy. Mol Immunol 47: 1650-1660, 2010.

WANG F, YANG L, GAO Q, HUANG L, WANG L, WANG J, WANG S, ZHANG B, ZHANG Y: CD163+CD14+ macrophages, a potential immune biomarker for malignant pleural effusion. Cancer Immunol Immunother 64: 965-976, 2015.

WEISBERG SP, MCCANN D, DESAI M, ROSENBAUM M, LEIBEL RL, FERRANTE AW JR: Obesity is associated with macrophage accumulation in adipose tissue. J Clin Invest 112: 1796-1808, 2003.

ZANNI MV, BURDO TH, MAKIMURA H, WILLIAMS KC, GRINSPOON SK: Relationship between monocyte/macrophage activation marker soluble CD163 and insulin resistance in obese and normal-weight subjects. Clin Endocrinol (Oxf) 77: 385-390, 2012.

ZEYDA M, FARMER D, TODORIC J, ASZMANN O, SPEISER M, GYORI G, ZLABINGER GJ, STULNIG TM: Human adipose tissue macrophages are of an anti-inflammatory phenotype but capable of excessive pro-inflammatory mediator production. Int J Obes (Lond) 31: 1420-1428, 2007.

ZIEGLER-HEITBROCK L: The CD14+ CD16+ blood monocytes: their role in infection and inflammation. $J$ Leukoc Biol 81: 584-592, 2007. 